\title{
Investment Risks Reduction of Developing Coal Deposits on the Basis of Quantitative Assessment Method of the Geological Information Confidence
}

\author{
Aleksandr Kopytov \\ T.F. Gorbachev Kuzbass State \\ Technical University \\ Kemerovo, Russia \\ kai.spssh@kuzstu.ru
}

\author{
Tamara Rogova \\ T.F. Gorbachev Kuzbass State \\ Technical University \\ Kemerovo, Russia \\ rogtb@mail.ru
}

\author{
Sergey Shaklein \\ Kemerovo branch of the Institute of \\ Computational Technologies SB RAS \\ Kemerovo, Russia \\ svs1950@mail.ru
}

\begin{abstract}
Approaches to the assessment of mining risk, which is the risk of subsequent disconfirmation of the quantity and conditions of the coal reserves existence, are given and summarized in the paper. It is shown that the methods of its assessment are developing in the way of quantitative methods application. It is indicated that geostatistical methods, which are widely used to assess the confidence of reserves, are not effective with coal deposits. The essence of the geometric method, which is more effective with coal deposits, is shown. This method is recommended to be used in Russia and within international expertise of coal reserves.
\end{abstract}

Keywords-investment risk, mining risk, quantitative assessment methods, confidence of mineral reserves, coal deposits

\section{INTRODUCTION}

It is known that to maximize its market price is the most important overall goal of the company's management for the shareholders [1]. The value of this price is determined by a variety of different factors. The specific feature of the price assessment of enterprises and companies in mining industries is the mineral resource base. Investigations [1] established the high importance of mineral resource base, it turned out that other things being equal and variations of the market price of the largest mining companies by $66-92 \%$ were due to the change in the value of mineral assets. The state assessment of the mineral resource base is always used by investors to determine the investment attractiveness of the project, as well as, when quoting the value of the shares of enterprises and when making decisions whether to sale, to hold an IPO, to assign rights and so on.

Actually, the cost of the mineral resource base is determined by its size and the market value of the raw materials. At present, Russia has begun to accumulate systematically statistical data on the valuation of already developed sites of subsurface reserves for the first time. Starting from the reporting period of 2016, enterprises conducting exploration and production of minerals are required to submit an annual form of federal statistical observation № 1-RIMR "Information on the current market value of mineral resources" in which the current market value of mineral reserves is determined by the size of the total discounted net cash flow [2]. This form of reporting should be provided only by those coal-mining enterprises which have resources of anthracite and hard coal in the amount of more than 25 million tons, or brown coal reserves in the amount of more than 50 million tons. It was investigated [3] that for coal deposits the price ratio per ton of resources to the average annual price varies in time from 0.10 to 0.14 .

Geological and mining-geometric information, on the basis of which the projects to open deposits are developed, is always distorted by errors objectively existing in the exploration process. As a result, there is always information inaccuracy, leading to the specific form of strategic investment risk - so-called mining or geological risk, which has many forms [4]. According to the survey, conducted by the Management and Economics Society of the Canadian Institute of Mining, Metallurgy and Petroleum (CIM MES) in 2003, it was found out that the leading industry analysts identified this type of risk as the most important for the mining business, and its significance was three times higher than the significance of the "raw materials market price" risk [5]. According to experts from South Africa [6], mining risk also refers to the most significant, but equally important "raw materials market price" risk.

This is especially important for the coal industry, which continues to develop both qualitatively and quantitatively. In the first 13 years of this century, coal mining has increased in the world as much as it did in the entire 20th century. The world has already explored a significant part of coal deposits, the most promising of which are located in 70 countries. Almost 55\% of all reserves are located in China and Russia. For many years, China (46-49\%) occupies the leading position in coal production in the world, where only one-seventh of the existing deposits are being developed and coal is mainly used for domestic consumption. The forecast of the world energy from the International Energy Agency WEO-2016 and the Russian "Forecast-2016" of the Analytical Center under the Russian Government suggest the reduction in the share of coal and oil in the energy consumption in the world by 2040 . However, the forecast options, both taking into account and not taking into account the current climate obligations of countries under the Paris Agreement, imply an increase in the consumption of these energy resources in absolute terms. It means that the problems of coal industry investing aimed to supply the retiring capacities and to expand them will remain relevant for a long time, especially in the leading production countries such as China, the United States, India, Australia, Indonesia, Russia, South Africa, Poland, Kazakhstan. 


\section{INTERNATIONAL APPROACHES To AsSESS THE CONFIDENCE OF GEOLOGICAL INFORMATION As THE SOURCE OF MINING RISK}

The extremely high importance of mining risk determines the obligation of its assessment and bringing its results to the investors' attention; it is stipulated by international systems of financial reporting and assessment. This requires the development of business-oriented global standards to assess the resources and mineral reserves. The leading role in standards creation belongs to the Committee for the Development of International Standards for Public Reporting on Resources and Reserves of Solid Minerals (CRIRSCO). This Committee, on the basis of the Australasian Code of accountability of exploration results, mineral resources and ore reserves JORC, developed the International Template for Reporting on the results of geological exploration, mineral resources and mineral reserves of solid minerals, the current version of which was adopted in November 2013 [7].The principles, approaches and definitions defined by this template are used in the national reporting standards of CRIRSCO member countries, which are currently Australasia (Australia and New Zealand), Brazil, Indonesia, Kazakhstan, Canada, Mongolia, Russia, the USA, Chile, South Africa and Pan- European Committee of the RERC, uniting the countries of Western Europe. As mutually agreed, the CRIRSCO codes differ only in view of the national peculiarities of the organization of mineral resources usage. For example, the Russian NAEN Code specifies, among others, that it is obligatory to conduct state geological expertise of mineral reserves and state registration; The Chilean Code states that unlike other countries, the status of a Competent Person who has the right to assess reserves and resources is governed by the laws of that country (Law of Chile № 20.235 of December 31, 2007), and so on.

When the investors want to assess the degree of mining risk they need information, based on classification of resources (closed to the Russian notion "Balance reserves", accounted for by the State Balance of Mineral Reserves and Resources) and reserves, subject by the project to economically justified extraction from the deposits, determined with allowance for clogging and dilution during mining. The CRIRSCO classification identifies three resource categories: inferred, indicated and measured, as well as two categories of reserves: probable and proved, with no reserves allocated in the contours of the location of the intended resources.

Without discussing any definitions, it should be noted that the degree of study of the least reliable inferred resources is such, that information about them is not recommended to be used in any technical and economic calculations. The investor understands that, guided by the expected inferred resources, he will act in conditions of very high mining risk, and the real value of such resources can be determined only after additional exploration works. The indicated and measured resources have truthfulness, which already allows to prove the planning development and to carry out an assessment of the economic viability of the field. However, if the indicated resources allow developing only an enlarged mining enterprise project, then the measured resources provide detailed development planning and, accordingly, the final assessment of the field economic viability. Of course, investing in enterprises with the specified resource categories has a different degree of risk.
These differences can be visually represented by the results of studies [8], performed with reference to gold deposits (there is no analogous studies on coal deposits). From the obtained results of this work, on the basis of the real data of transactions to purchase the deposits by the Russian company "Polymetal International plc", it is clearly seen that if to accept the price of gold in the subsurface in the inferred resources for 1 , then in the indicated resources it will be 4 , and in the measured resources it will be 12 . In addition, the indicated ratios demonstrate that the geological exploration works is a very effective tool to increase the capitalization of mining business.

Proved reserves (expected output) are essentially allocated in the measured resources framework. There must be confidence that the technical, technological, legal, environmental and other types of conditions (the so-called modifying factors) have been determined reliably and cannot significantly affect the level of extraction of these reserves from the deposit. Probable reserves have a lower level of confidence, because they are allocated in the contour of indicated resources. In addition, the reserves are also included in this group, allocated in the measured resources framework, if there is no full assurance of their extraction at the expected level due to doubts about the full reliability of technical, legal, environmental and other modifying factors.

Such a scheme for presenting data of integrated assessment of mining risk to investors is fully justified and well perceived by investors. In its implementation, the method of expert evaluations is widely used, to the merits of which one can attribute the speed of obtaining results and the possibility of research based on the synthesis of experience and intuition.

However, there is a question about the order and resources qualification reliability of a particular category. The current CRIRSCO reporting codes allow an independent qualified specialists (called the competent person) to classify resources and reserves. The requirements to these specialists are high enough, unified and presented in the Codes in detail. To facilitate the work of the competent persons, the Codes contain detailed, but not comprehensive lists of control questions to be considered. In general, the CRIRSCO methodology for conducting the examination coincides with the methodology used by the Russian State Commission for Mineral Reserves (GKZ).

The requirement, recoded in the Codes, that not every specialist can actually make assessment and inform investors about the reliability of geological data, in fact, is aimed to exclude the possibility of investors deception, as there were some cases of fraud. The largest of them was an example of the gold copper mine "Busang" in Indonesia; in result investors were deceived by the presented data on its "resources" (3-4\% of the global resources) and lost, by the most conservative estimates, at least $\$ 1.5$ billion, invested by them into "Bre-X Minerals" company. It is important that in this fraud there is also a corruption component. Perhaps "Bre-X Minerals" hired Sigita Khardzhoyudanto (the oldest son of that time Indonesian President Suharto) not that easy with a monthly salary of $\$ 1$ million and the right to receive $10 \%$ from future gold mining.

At the same time, the expert assessment, in one way or another, is always subjective, especially when natural geological formations are assessed, as each is unique in its 
own way. There were some cases when the conclusions formulated by experts were not confirmed by practice, and investment projects proved to be untenable. So, in December 2014, the shareholder of the Hong Kong-based Siberian Mininig Group, Charles Chih, sued the Supreme Court of Hong Kong for a refund of $\$ 280$ million in connection with a misassessment of the "resources" of the "Mine Lapichevskaya-2" in Kuzbass. This assessment was carried out in compliance with all applicable standards of the world's largest international consulting company, operating in the mining sectors, but proved to be wrong.

In addition, it should be taken into account that the expert's point of view can be deliberately distorted as a result of the corrupt influence both directly on him and on the structures and persons, providing information support of his activities. Currently, the fight against corruption manifestations, both in Russia and in the world, is given the most serious attention. A group of UK and US high-ranking experts with extensive experience in preventing and investigating fraud cases believe that modern "mining is classified as one of the sectors with a high corruption risk" [9] and point the existence of corruption-related risks of assessing "resources" and the loss of licensing rights to develop deposits.

\section{QUANTITATIVE METHODS APPLICATION TO ASSESS THE CONFIDENCE OF GEOLOGICAL INFORMATION}

An effective tool to improve the quality of resources expertise and to reduce corruption risks is quantitative methods to assess the confidence of exploration results and field modeling. However, all the current Resource Assessment Codes provide only an opportunity, but not a obligatory application. In contrast to them for the first time in the world the effective Russian National Classification of Reserves and Prognostic Resources of Solid Minerals (put into operation since 2008) calls for the mandatory application of quantitative methods to assess the reliability of reserves when classifying them. In 2010 this case was highly appreciated by CRIRSCO with the approval of the Guidelines on the Alignment of Russian Minerals Reporting Standards and the CRIRSCO Template, and also in 2011 when adopting Russian Code for the Public Reporting of Exploration Results, Mineral Resources and Mineral Reserves (the NAEN Code), which is the full Code of the CRIRSCO family.

Unfortunately, until now the requirement for obligatory application of quantitative methods in the classification of reserves is not being observed: the Federal Agency for Subsurface Use and the executive bodies of the Subjects of the Federation (regarding subsurface areas of local significance) continue to approve the results of geological expertise of coal reserves, which geological materials do not at all contain the results of a quantitative assessment of their reliability, i.e., violate the requirements of the state classification. Paradoxically, thereby they ignore state requirements, which, from a formal point of view, turn decisions about approving reserves and putting them on state records in illegitimate ones. Taking into account that in accordance with the law of the Russian Federation "On Subsurface reserves", the lack of state expertise does not allow staging reserves for state registration and, ultimately, leads to illegal mining; such violations by state bodies create additional risks for subsurface reserves users and investors.
Thus, for example, there was a case when the given, artificially created risk, served as a reason to decrease the price of the sold asset. It is extremely simple to establish the fact of the violation in this question. In accordance with article 16-7 of the current requirements to the composition of geological materials [10], the geological report should indicate "quantitative and probabilistic methods used to justify the categories of reserves to estimate the accuracy and reliability of determining the main parameters for the calculation of resources, the results of their application (can

be included in the text applications), the reasons and justification for the adoption of categories that differ from the categories recommended by the results of a quantitative and probabilistic assessment". If there is no such information

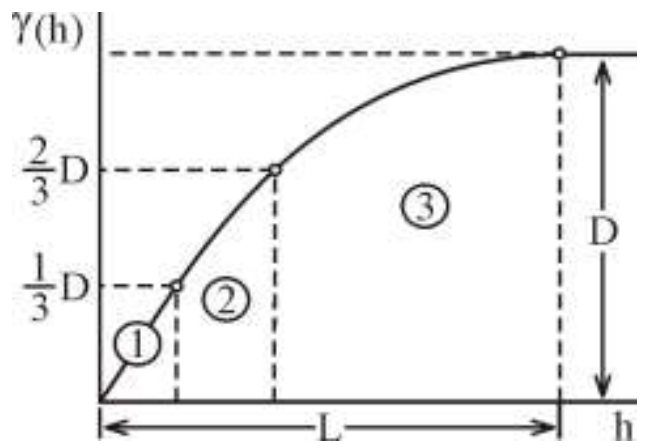

Fig. 1. Variogram of a continuous spatial variable

in the report, it means that the requirements for classification of reserves are not fulfilled. This circumstance must be taken into account by the investor.

To carry out quantified assessment of resources confidence in order to determine their categories, methods primarily based on geostatistical approaches are used [11]. The most widespread (about $75 \%$ of all foreign expertise) became simple methods based on the analysis of variograms [12]. Simply assessing the continuity of the studied geological characteristics, the variogram reflects the nature of the variation of $\gamma(\mathrm{h})$ values of the characteristic at points located at a certain distance $\mathrm{h}$ from the measurement point, which allows estimating the error of field modeling [13]. As the distance from the geological prospecting well increases, the value of the characteristic under study begins to differ more and more from the value measured in it, and at a distance of the influence interval $L$ this difference becomes approximately constant and equal to the differences of the unit values of the characteristic from their average value the threshold D (Figure 1). With a distance greater than L, it is generally impossible to assume how the characteristic at such deletions behaves.

In general, the assessment of resource categories according to the analysis of the variogram is carried out by the distances between the points of measurement of the geological characteristic. The limiting distances between the wells for each category are determined from the value of the variogram $\gamma(\mathrm{h})$, at which it reaches a specified fraction from threshold D. The fraction value is usually taken [14] 1/3 from $\mathrm{D}$ for the measured resources, from $1 / 3$ up to $2 / 3$ for indicated resources and more than $2 / 3$ for inferred resources (respectively, zones 1, 2 and 3 zones in Figure 1). The expert has the right to establish the relationships that are different from those given. In addition, information on the minimum number of measurements participating in the interpolation is 
often additionally used (usually block of a block model of the field refers to the measured resources, if this number exceeds 3-5, and refers to the indicated if it is not less than 2 [15]).

However, the geostatistical approaches application is a complex procedure, the results of which are influenced by various factors: the influence of the accepted variogram model, the anisotropy of the characteristic and the degree of its stability, the scale effect, the inequality of the observation network, etc. The manifestation of these factors is characteristic of coal deposits. It is this circumstance that leads to the fact that for such deposits geostatistics has a low efficiency, and the results obtained with its help are often not reliable. A number of specific features of coal fields have even required the development of additional standards, which include, in particular, the Australian Guideline for the Assessment and Classification of Coal Resources [16], the processes and procedures stated in which are recommended by the JORC Code. This guideline indicates that a variogram can only help in determining the distances of continuity between observation points and "it is not suitable for it, since it does not take into account all other necessary factors" [16].

Special methods for quantitative assessment of the geological information confidence of coal deposits

The low efficiency of geostatistical methods application in coal deposits led to geometric methods application. The simplest of them, based on the estimation of the marginal removal of the boundaries of resource contours from wells, is used in the US national classification [17]. According to this classification, a contour distant from the well for 2 furlongs $(402 \mathrm{~m})$ refers to the measured resources; a contour distant from the well for 6 furlongs refers to indicated resources and a contour distant from the well to 24 furlongs refers to inferred resources. This approach has the right to exist, since the reliability of the results of subsurface reserves studies depends, on the whole, on the complexity of the geological structure of formation and on the density and configuration of the network of exploratory wells, through which it has been studied. In conditions of very simple structure of coal deposits in the USA, the factor of complexity can obviously be neglected. In the USSR, the distances between the wells were used as the main criterion for categorizing reserves only until 1953 (in the classifications of 1927, 1933 and 1941). Since the vast majority of coal deposits have great complexity, the American national approach to their assessment is completely inapplicable.

To assess the reliability of coal deposits a special geometric approach, based on the use of the theory of the geochemical field, was proposed at the beginning of the last century by prof. P. K. Sobolevsky, main terms of this approach are close to the terms developed much later in geostatistics. The basis of the developed approach is based on two simplest considerations [18].

Firstly, it is known that at every "point" of the coal seam, any characteristic (elevation grade of the bed floor, its thickness, ash content, etc.) actually takes only one single value. It means that a model, that ideally describes the behavior of the exponent, must also have the property of uniqueness. Therefore, the ambiguity of the model is evidence of its inadequacy to the real object. Moreover, the degree of this inadequacy is greater, the more the model is ambiguous. Thus, the assessment of the reliability of the geological model can be carried out through a quantitative assessment of its ambiguity.

Secondly, the actual ambiguity of any constructions can be quantified only in the presence of excessive measurements. But they are extremely undesirable, because they appear as a result of re-exploration of a geological object. Therefore, it was suggested to create such measurements in the form of artificial indirect redundant determinations.

Thus, the general scheme for assessing the reliability of geological materials is in creation of indirect redundant determinations, on their basis quantity assessment of the ambiguity degree of the analyzed model, with movement from ambiguity estimation to an estimation of the model's reliability (error).

Within the framework of this approach, three ways of creating redundant determinations are proposed. The main one is the method, which consists in dividing the network of wells into a system of intersecting arching quadrangles with vertices - wells. In each quadrangle there are two diagonals intersecting at one point. Then interpolated method, corresponding to the accuracy of the method used in constructing the analyzed model, determines the value of the exponent at this point for each diagonal and their variation, which is regarded as a measure of the ambiguity of the construction, i.e. as some criterion for reconnaissance. As a result of the studies, a statistical interrelation between the values of these criteria and the real errors of the mining and geometric models of the deposits was established. The other two methods for creating redundant measurements and, accordingly, assessment of modeling errors are focused on solving specific issues: assessing the reliability of the proposed position of the seam along the line of exploratory holes and estimating the error in the average value of the characteristic in the given area.

The approach provides an opportunity to assess the continuity of the object, which is given fundamental importance by the CRIRSCO family codes, in the form of assessment of the interpolating values legitimacy of characteristics in the inter-well space. Unlike geostatistical methods, the geometric approach is operative in conditions of an uneven network of observations and the manifestation of anisotropy of the evaluated characteristic, and protected from manifestations of the scale effect. Moreover, local zones of the concentration of the well network (sections of detailing) allow to perform by strictly formalized methods the pre-training of the confidence rating algorithm and thereby to improve its quality. For the same purposes the data of the mining operations already carried out at the site can be used. This approach allows to take into account such a factor, which is difficult to assess with the help of geostatistics, as the degree of fracture study of coal seams. Comparison of the results of assessing the reserves confidence with mining data of Kuzbass mines has shown that the application of the developed approach makes it possible to increase the reliability of resources categorization by three to four times in comparison with the categorization performed by the traditional expert method. The application of this geometric approach is possible only if it is appropriate to interpolate the values of the studied indicators in the space between geological exploration wells. To assess its feasibility, special methods are used [19]. 
The approach is implemented in the form of guidance notes [19] and the corresponding software [20]. The notes were reviewed by the State Commission on Mineral Reserves and recommended for practical use to assess the reserves submitted for state geological expertise. They are also recommended to be use by the Society of Russian Experts on Subsoil Use (OERN), officially recognized by the CRIRSCO member countries as the Recognized Professional Organization (RPO). In accordance with the articles of the NAEN Code, this is the official permission to use the notes [18] to perform the resources expertise according to international standards.

The assessment of resources confidence by the method under consideration provides a separate assessment of the degree resources confidence by various factors (the standard set of assessments includes the obligatory consideration of the reliability of ash content study, capacity and hypsometry
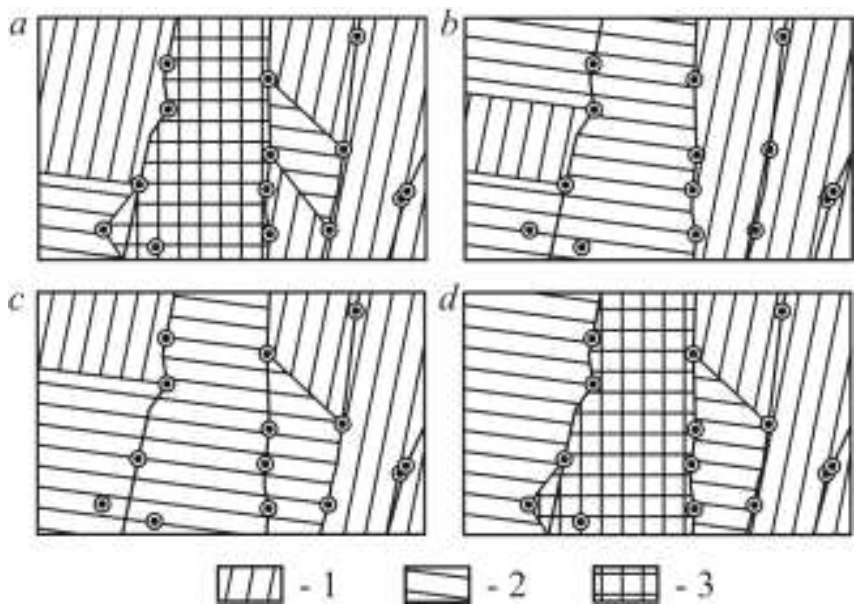

Fig. 2. Fragments of the actual cartograms of coal seam exploration (a for hypsometry, b - for seam thickness, $\mathrm{c}$ - for ash content, $\mathrm{d}$ - total): 1 and 2 - measured reserves, respectively, requiring and not requiring operational exploration; 3 - indicated reserves

of the seam, including its fracture, but may be expanded if necessary).

As a result of calculation of the extent of exploration criteria, so-called exploration maps for each factor are formed, in which resources of various degrees of confidence are colored differently. If necessary, the resource categories can be specificated. For example, in Fig. 2 the measured resources are divided into two subgroups: requiring and no longer requiring of mining exploration before mining. Investors oriented on short-term investments are usually interested in this division.

In general, the fragmentation of the integral characteristic of the resources confidence due to the reasons (factors) attributing them to a particular category is useful for an investor, since in addition it allows to correlate the subsoil user's marketing strategy with the information reliability. For example, if a subsoil user is working on resources with poorly studied ash content, being guided by its supplies to the cement industry (which does not require high quality requirements), then this will be less risky than in case of his orientation on deliveries of coal to power units. In addition, factorial detailing of assessment allows subsoil users to choose the most rational ways to increase the reliability of geological data about the mineral resource base at their disposal, and ultimately to accelerate business capitalization.
At the final stage of the analysis, all the cartograms are superimposed on each other and, by adopting the lowest estimates of factors for contours, a final integrated map is formed, which is the result of a quantitative assessment of the resources confidence (Figure 2, d). It is the basis for the further work of an expert, who has the right to adjust the obtained results, but under the conditions specified by the requirements [1] - obligatory description of the reasons and justification for the adoption of categories that differ from the categories recommended by the results of the quantitative assessment. This requires the expert not only to present his opinion, but also to justify it which clearly increases the objectivity of the expertise.

\section{CONCLUSION}

Based on the foregoing, it should be admitted that quantitative methods to assess the confidence of resources are the instrument, the application of which doesn't only improves the quality of their categorization and, accordingly, the assessment of mining risk, but also reduces the potential corruption-related character of expert activities.

In the conditions of coal deposits, geostatistical methods for assessing the reliability of geological models can produce distorted results. In such conditions, geometric methods for estimating reliability that do not require fine tuning should be used to perform reserves categorization. In addition, they allow you to assess the most important factor, that is the reliability of the study of hypsometry and the faulted coal seams.

When deciding on the assessment of a mining risk when investing in facilities located in Russia, it is recommended that attention be paid to the availability in the geological documentation of information on the use of quantitative methods for assessing the reliability of the field's reserves their absence indicates that there is a risk, albeit low, of the recognition of mining operations in the mining site illegal and their suspension prior to the implementation of geological expert examination of the newly prepared geological report.

\section{REFERENCES}

[1] Andreeva, K. R. Accounting, analysis, audit and statistics: fundamental and applied scientific researches. Scientific papers on the materials of the Ist International Scientific and Practical Conference, 2016, 15-21.

[2] The order of the Federal Service of State Statistics dated. 2017 (70)

[3] A.V. Dushin, B. A. Taktashkin, The Economy of the Region[J]. 2013, (1) 88-95.

[4] T.B. Rogova, S. V. Shaklein, Management and Business Administration[J]. 2010 (1) 90-95.

[5] T.A. Knyazeva, Abstract from Ph.D. thesis in economics. Financial Academy under the Government of the Russian Federation, 2005

[6] J. Simensen, J. Perry Journal of the Southern African Institute of Mining and Metallurgy[J]. 1999, 99(6), 321-329

[7] The International Template for Reporting of Exploration Results, Mineral Resources and Mineral, Reserves Committee for Mineral Reserves International Reporting Standards, 2013

[8] S.V. Petrov, I.D. Kotlyarov, A.B. Katznelson, M.S. Sen Enrichment of ores[J]. 2016, (2) 3-8.

[9] A. Woolich, N. Hutton, G. Denny, O. Isaacson. G. Martin, C. Muzabazi, Mining Journal[J]. 2014, (11), 17-32

[10] Order of the Ministry of Natural Resources of Russia, 2011 (378)

[11] A. Arik, 30 International Symposium on the Application of Computers and Operations Research in the Mineral Industry, 2002 
[12] [12] D. S. F.Silva, Abstract from Ph.D. thesis in mining engineering. Department of Civil and Environmental Engineering University of Alberta. Edmonton, 2015

[13] Yu. E. Kaputin, A.I. Ezhov, S. Henley, Geostatistics in mining and geological practice[M]. Mining Institute of the Kola Scientific Center of the Russian Academy of Sciences, 1995

[14] [14] J. Mucha, M. Wasilewska-Błaszczyk, Górnictwo Odkrywkowe. 2014, 2(3), 67-73.

[15] V.I. Shcheglov, Geostatistical methods of analysis and estimation of deposits. South-Russian State Technical University, 2012

[16] Guidelines Review Committee on behalf of the Coalfields Geology Council of New South Wales and the Queensland Resources Council, 2014
[17] Coal Resource Classification System of the U.S. Geological Survey: Geological Survey Circular 891.

[18] T.B. Rogova, S.V. Shaklein, The confidence of coal reserves. Quantitative assessment and monitoring[M]. LAP LAMBERT Academic Publishing GmbH \& Co, 2011

[19] T.B. Rogova, O.P. Nikiforova, S.V. Shaklein, Methodological recommendations on the quantitative assessment of the correspondence degree of geological models of the coal deposit to its true state[M]. Kemerovo, 2011

[20] S. V. Shaklein, T.B., Rogova. Certificate of state registration of the computer program №. 2013618149. MDZ - Monitoring of coal reserves reliability, 2013 